\title{
An Examination of the Antibacterial, Antifungal, Anti-Giardial and Anticancer Properties of Buchanania obovata Engl. Fruit Extracts
}

\author{
Cécile Mazerand ${ }^{1,2}$, Ian Edwin Cock ${ }^{1,3 *}$ \\ 'School of Environment and Science, Griffith University, Brisbane, 4111, AUSTRALIA. \\ ${ }^{2}$ School of Biology, Ecole de Biologie Industrielle (EBI), Cergy, FRANCE. \\ ${ }^{3}$ Environmental Futures Research Institute, Griffith University, Brisbane, AUSTRALIA.
}

\begin{abstract}
Background: Buchanania obovata is an endemic Australian plant that has been used traditionally to treat a variety of bacterial, fungal and protozoal pathogenic diseases. This study was undertaken to test $B$. obovata fruit extracts for the ability to inhibit microbial and cancer cell growth. Materials and Methods: B. obovata fruit powder was extracted and tested for antimicrobial activity using disc diffusion and MIC methods. Inhibitory activity against the gastrointestinal protozoal parasite Giardia duodenalis and antiproliferative activity against human colorectal (Caco2) and cervical (HeLa) cancer cell lines was evaluated using MTS-based colorimetric assays. Toxicity was evaluated using an Artemia franciscana nauplii bioassay. Results: The methanol, water and ethyl acetate B. obovata fruit extracts displayed potent antibacterial activity. The methanol and water extracts displayed the broadest specificity, inhibiting the growth of all of the Gram positive and Gram negative bacterial species tested. The ethyl acetate extract also displayed antibacterial activity, inhibiting the growth of 7 (88\%) of the Gram negative and $2(50 \%)$ of the Gram positive bacterial species. The methanol extract also displayed broad spectrum antifungal activity, inhibiting the growth of all 3 fungal species, including an ampicillin resistant strain of $A$. niger. The water extract also inhibited the growth of $2(66 \%)$ of the fungal species tested. None of the extracts were particularly good
\end{abstract}

inhibitors of the growth of the gastrointestinal parasite Giardia duodenalis. The methanolic and aqueous extracts were effective at blocking the proliferation of the colorectal cancer cell line $\mathrm{Caco} 2$ to between approximately 20 and $30 \%$ of the untreated cell growth. All extracts also inhibited HeLa cervical cancer cell growth. The methanol, water and ethyl acetate extracts displayed substantial toxicity in the Artemia nauplii assay. Conclusion: This study shows that $B$. obovata fruit extracts inhibit bacteria and fungi, but are relatively ineffective against $G$. duodenalis. The extracts were also effective inhibitors of $\mathrm{CacO} 2$ and HeLa cell proliferation, indicating that the extracts have potential in the treatment of microbial diseases and some cancers. Key words: Antibacterial activity, Green plum, Giardia duodenalis, Antiproliferative activity, Anticancer activity, Artemia, toxicity.

\section{Correspondence:}

Dr. Ian Edwin Cock

School of Environment and Science, Griffith University, Brisbane,

4111, AUSTRALIA.

Tel: +61737357637

E-mail: I.Cock@griffith.edu.au

DOI: 10.5530/pc.2019.1.3.

\section{INTRODUCTION}

Plants have been used medicinally for thousands of years by most if not all civilisations globally. These traditional medicines have uses to treat a wide variety of different diseases and medical complaints, including many pathogenic diseases. Phytotherapy in Asia is widespread and is particularly well documented. Ayuverda and traditional Chinese medicine (TCM) continue to be the primary therapeutic option for large percentages of the Indian and Chinese populations respectively and many other Asian ethnic groups are reliant on regional medicine systems. Furthermore, the efficacy of many of the Asian plant medicines have been verified by scientific examination. ${ }^{1-2}$ Similarly, plant based medicinal systems continue to be the primary therapeutic option in many parts of Africa. For example, numerous African plant have antibacterial activity and potential for the treatment of some inflammatory diseases. ${ }^{3-4}$ Similarly, numerous southern African plant species are used in the control of parasites, worms, helminths and ectoparasites etc. ${ }^{5}$ Whilst the medicinal properties of Australian plants are less extensively documented and reported than for other regions of the world, there has been substantial recent interest in traditional Australian medicines. Recent publications have reported antibacterial, ${ }^{6-7}$ anti-Giardial, ${ }^{8-9}$ antiviral ${ }^{10}$ and anticancer ${ }^{11}$ activity of some plants used medicinally by the first Australians. Numerous other Australian plants used medicinally by first Australian groups are yet to be examined for their therapeutic properties.

Buchanania obovata Engl. (family Anacardiaceae), commonly known as green plum or wild mango, is an Australian plant which is endemic to the woodland regions of northern Australia. It is a small to medium sized tree that grows in the shaded understorey of those forests. B. obovata produces small round fleshy fruit with smooth green skin, approximately $1-1.5 \mathrm{~cm}$ in diameter. The fruit contain high levels of antioxidants and were considered to be a nutritious food by the first Australians. Despite its common name of green plum and its high antioxidant capacity, this species should not be confused with Terminalia ferdinandiana Exell. (Commonly known as Kakadu plum), which also produces small fruit with high antioxidant levels. B. obovata was used by the first Australians as a bacteriocide to treat wounds, sores and ulcers. ${ }^{12}$ The same text also records the use of $B$. obovata to treat eye disease, skin disease and diarrhoea. Bacterial pathogens are major causes for all of these conditions, yet studies examining the antibacterial properties of B. obovata fruit are lacking. Diarrhoea may also be caused by non-bacterial pathogens such as Giardia duodenalis, yet studies against this pathogen are also lacking. The current study was undertaken to screen B. obovata fruit extracts against a panel of bacterial pathogens and against $G$. duodenalis. Furthermore, as high antioxidant activities have been linked with anticancer activity, ${ }^{13}$ the antiproliferative activity of $B$. obovata fruit extracts was also evaluated against two human cancer cell lines.

\section{MATERIALS AND METHODS}

B. obovata fruit were collected on Groote Esylandt, Australia in November 2013 and was stored at $-30^{\circ} \mathrm{C}$ until processing. Gayangwa Lalara and Gwen Lalara, elders of the Warnindhilyagwa tribe on Groote Esylandt, identified the trees and provided the fruit. The flesh of the fruit was cut into small pieces and dried in a Sunbeam food dehydrator. The dried pieces were subsequently ground into a coarse powder and extracted by standardised methods ${ }^{6-7}$ Briefly, a mass of $1 \mathrm{~g}$ of powdered plant material was weighed into each of five tubes and five different extracts were 
prepared by adding $50 \mathrm{~mL}$ of methanol, water, ethyl acetate, chloroform or hexane respectively. All solvents were obtained from Ajax Fine Chemicals, Australia and were AR grade. The B. obovata fruit material was extracted in parallel in the individual solvents for $24 \mathrm{hrs}$ at $4^{\circ} \mathrm{C}$ with gentle shaking before being filtered through Whatman No. 54 filter paper under vacuum. The solvent extracts were dried by evaporation in the shade, whilst the aqueous extract was dried by lyophilisation. The resultant dry extracts were weighed and redissolved in $10 \mathrm{~mL}$ deionised water (containing 1\% DMSO).

\section{Qualitative phytochemical studies}

Phytochemical analysis of B. obovata fruit extracts for the presence of phenolic compounds, cardiac glycosides, saponins, triterpenoids, polysterols, alkaloids, flavonoids, tannins and anthraquinones was conducted by standard assays. ${ }^{14-16}$

\section{Antioxidant capacity}

The antioxidant capacity of each extract was assessed using the DPPH free radical scavenging method ${ }^{11,13}$ with modifications. Briefly, $2 \mathrm{~mL}$ aliquots of each test and reference sample (in $2 \mathrm{~mL}$ of methanol) were added to a 96 well plate in $5,10,25,50,75 \mu \mathrm{L}$ volumes. All tests were performed three times in triplicate $(n=9)$. Methanol was added to each well to give a volume of $225 \mu \mathrm{L}$. A volume of $75 \mu \mathrm{L}$ of DPPH solution (400 $\mu \mathrm{M}$; Sigma Australia; prepared in in AR grade methanol, Ajax, Australia) was added to each well, giving a total reaction volume of $300 \mu \mathrm{L}$. Ascorbic acid was also tested in parallel across the range $0-25 \mu \mathrm{g}$ per well as a reference and the absorbance's were recorded at $515 \mathrm{~nm}$. The antioxidant capacity based on DPPH free radical scavenging ability was determined for each extract and expressed as $\mu \mathrm{g}$ ascorbic acid equivalents per gram of original plant material extracted.

\section{Antibacterial screening Test bacteria}

Acinetobacter baylyi ATCC 33304, Proteus mirabilis ATCC 33044, Proteus vulgaris ATCC 21719, Escherichia coli O157 H7 and Staphylococcus aureus ATCC 157293 were obtained from the American Type Culture Collection (ATCC), USA. The clinical bacterial strains Aeromonas hydropholia, Alcaligenes faecalis, Bacillus cereus, Pseudomonas fluorescens, Staphylococcus epidermis and Streptoccocus pyogenes were obtained from the School of Natural Sciences teaching laboratory at Griffith University.

\section{Test fungi}

Clinical strains of Aspergillus niger, Candida albicans and Saccharomyces cerevisae were obtained from the School of Environment and Science teaching laboratory at Griffith University. All fungal species were grown and subcultured in Sabouraud broth (Oxoid, Australia). A. niger were grown at room temperature for $48 \mathrm{hrs}$, whilst C. albicans and $S$. cerevisae were grown at $37^{\circ} \mathrm{C}$ for $24 \mathrm{hrs}$.

\section{Evaluation of antimicrobial activity}

The antimicrobial activity of all of the plant extracts was determined using a modified disc diffusion method. ${ }^{17-18}$ Briefly, $100 \mu \mathrm{L}$ of the test bacteria or fungi were grown in $10 \mathrm{~mL}$ of fresh nutrient broth or Sabouraud broth respectively until they reached a count of approximately $10^{8}$ cells $/ \mathrm{mL}$, as determined by direct microscopic determination. Individual microbial suspensions $(100 \mu \mathrm{L})$ were spread onto the appropriate agar plates. The extracts were tested using $6 \mathrm{~mm}$ sterilised filter paper discs. Discs were infused with $10 \mu \mathrm{L}$ of the test sample, allowed to dry and placed onto inoculated plates. The plates were allowed to stand at $4^{\circ} \mathrm{C}$ for $2 \mathrm{hrs}$ before incubation with the test microbial agents. All plates inoculated with bacteria and the plates inoculated with C. albicans or S. cerevisiae, were incubated at $37^{\circ} \mathrm{C}$ for $24 \mathrm{hrs}$ and the diameters of the zones of inhibition were measured. Plates inoculated with A. niger were grown at room temperature for $48 \mathrm{hrs}$, then the diameters of the inhibition zones were measured. All measurements were to the closest whole millimetre. Each antimicrobial assay was performed three times in triplicate $(n=9)$ and mean values were determined. Standard discs of ampicillin $(10 \mu \mathrm{g})$, chloramphenicol $(10 \mu \mathrm{g})$ and nystatin $(100 \mu \mathrm{g})$ were obtained from Oxoid Ltd. and served as antibacterial or antifungal positive controls. Discs infused with $10 \mu \mathrm{L}$ of distilled water were included as negative controls.

\section{Minimum inhibitory concentration (MIC) determination}

The minimum inhibitory concentration (MIC) of the B. obovata extracts were determined by the disc diffusion method across a range of doses. ${ }^{7}$ The plant extracts were diluted in deionised water (containing 1\% DMSO) across the concentration range $5 \mathrm{mg} / \mathrm{mL}$ to $0.1 \mathrm{mg} / \mathrm{mL}$. Discs were infused with $10 \mu \mathrm{L}$ of the test dilutions, allowed to dry and placed onto inoculated plates. The assay was performed as outlined above and graphs of the zone of inhibition versus ln concentration were plotted for each extract. Ln linear regression was used to calculate the MIC values.

\section{Inhibitory bioactivity against Giardia duodenalis trophozoites}

\section{Parasite culture}

The Giardia duodenalis S-2 (sheep strain 2) trophozoite strain used in this study was supplied by Professor Ann McDonnell, Griffith University, Australia. The G. duodenalis tropozoites were maintained and subcultured anaerobically at $37^{\circ} \mathrm{C}$ in TYI-S-33 growth media supplemented with 1\% bovine bile (Sigma), 10\% Serum Supreme (Cambrex Bioproducts) and $200 \mathrm{IU} / \mathrm{mL}$ penicillin $/ 200 \mu \mathrm{g} / \mathrm{mL}$ streptomycin (Invitrogen, USA). Confluent mid log phase cultures were passaged every 2 days by chilling the cultures on ice for a minimum of $10 \mathrm{~min}$, followed by vortexing to dislodge the adherent trophozoites from the walls of the culture vessel. Fresh culture media $(5 \mathrm{~mL})$ was seeded with approximately $1 \times 10^{5}$ trophozoites for each passage.

\section{Evaluation of anti-Giardial activity}

Anti-Giardial activity was determined as previously described. ${ }^{8-9}$ Briefly, $30 \mu \mathrm{L}$ of the test extracts or the vehicle solvent or culture media (for the negative controls) was added to trophozoite suspensions $(70 \mu \mathrm{L})$ containing approximately $1 \times 10^{5}$ trophozoites in 96 well plate and the plates were incubated anaerobically at $37^{\circ} \mathrm{C}$ for $12 \mathrm{hrs}$ in a humidified anaerobic atmosphere. CellTiter $96^{\circ}$ Aqueous One Solution Cell Proliferation Assay Reagent $(20 \mu \mathrm{L}$; Promega) was added to each well and the plates were incubated for a further $3 \mathrm{hrs}$. The absorbances were recorded at 490nm using a Molecular Devices, Spectra Max M3 plate reader. All tests were performed three times in triplicate $(n=9)$. The anti-proliferative activity of each test was expressed as a percentage of the negative untreated control.

\section{Screen for anti-cancer bioactivity Cancer cell lines}

The Caco2 and HeLa carcinoma cells used in this study were obtained from American Type Culture Collection (Rockville, USA) and cultured in Roswell Park Memorial Institute (RPMI) 1640 medium (Life Technologies), supplemented with $20 \mathrm{mM}$ HEPES, $10 \mathrm{mM}$ sodium bicarbonate, $50 \mu \mathrm{g} / \mathrm{mL}$ streptomycin, $50 \mathrm{IU} / \mathrm{mL}$ penicillin, $2 \mathrm{mM}$ glutamine and $10 \%$ foetal calf serum (Life Technologies). The cells were maintained as monolayers in $75 \mathrm{~mL}$ flasks at $37^{\circ} \mathrm{C}, 5 \% \mathrm{CO}_{2}$ in a humidified atmosphere until approximately $80 \%$ confluent. 


\section{Evaluation of cancer cell anti-proliferative activity}

Antiproliferative activity of the extracts was assessed using standard assays. $^{11,13}$ Briefly, cell suspensions $(70 \mu \mathrm{L}$, containing approximately 5000 cells (as determined by direct enumeration in a Neubauer chamber) were added to individual wells of a 96 well plate and $30 \mu \mathrm{L}$ test extracts or cell media (for the negative control) were added. The plates were incubated at $37^{\circ} \mathrm{C}, 5 \% \mathrm{CO}_{2}$ for $12 \mathrm{hrs}$ in a humidified atmosphere. Cisplatin (Sigma, Australia) was used as a positive control at a concentration of $50 \mu \mathrm{g} / \mathrm{mL}$ in the assay. The extracts were also tested across a range of dilutions and the results were plotted to allow for the determination of $\mathrm{IC}_{50}$ values. Following the incubation, $20 \mu \mathrm{L}$ of Cell Titre 96 Aqueous One solution (Promega) was added to each well and incubated for a further $3 \mathrm{hrs}$ at $37^{\circ} \mathrm{C}$. Absorbances were measured at 490nm using a Molecular Devices, Spectra Max M3 plate reader. All tests were performed in triplicate, each with 3 internal replicates $(n=9)$. The antiproliferative activity of each test was recorded as a percentage of the negative control.

\section{Artemia franciscana nauplii toxicity screening}

Toxicity was tested using a modified A. franciscana nauplii lethality assay. ${ }^{19-20}$ Briefly, $400 \mu \mathrm{L}$ of seawater containing approximately 45 (mean $44.6, \mathrm{n}=125, \mathrm{SD} 13.6)$ A. franciscana nauplii were added to wells of a 48 well plate and immediately used for bioassay. A volume of $400 \mu \mathrm{L}$ of diluted plant extracts or the reference toxin $(1000 \mu \mathrm{g} / \mathrm{mL}$ potassium dichromate) were transferred to the wells and incubated at $25 \pm 1^{\circ} \mathrm{C}$ under artificial light (1000 Lux). A negative control (400 $\mu \mathrm{L}$ seawater) was included on each plate. All treatments and controls were performed three times in triplicate $(n=9)$. The wells were checked at regular intervals and the number of dead were counted. After $24 \mathrm{~h}$, all nauplii were sacrificed and counted to determine the total $\%$ mortality per well. The $\mathrm{LC}_{50}$ with $95 \%$ confidence limits for each treatment was calculated using probit analysis.

\section{Statistical analysis}

Data are expressed as the mean \pm SEM of three independent experiments performed in triplicate $(n=9)$. One way ANOVA was used to calculate statistical significance between control and treated groups with a $P$ value $<0.01$ considered to be statistically significant.

\section{RESULTS}

\section{Liquid extraction yields, qualitative phytochemical screening and antioxidant capacity}

Extraction of $1 \mathrm{~g}$ of dried plant material with various solvents yielded dried plant extracts ranging from $43 \mathrm{mg}$ to $118 \mathrm{mg}$ (Table 1). Methanol and water extracted the highest yields of dried extracted material (108 and $118 \mathrm{mg}$ respectively). Ethyl acetate, chloroform and hexane extracted lower masses (approximately 69, 43 and 55mg respectively). The dried extracts were resuspended in $10 \mathrm{~mL}$ of deionised water, resulting in the extract concentrations shown in Table 1. Phytochemical studies (Table 1) showed that methanol and water extracted the widest range and largest amount of phytochemicals in this study. Both extracts contained high levels of phenolics, flavonoids and tannins, as well as low to moderate levels of saponins. Similar classes of phytochemicals were detected in the ethyl acetate extract, albeit at lower levels. In contrast, the chloroform and hexane extracts were generally lacking in detectable levels of all phytochemical classes. The methanolic, water and ethyl acetate extracts also had high antioxidant capacities, with with 38, 55 and $48 \mu$ g ascorbic acid equivalents per original gram of dried fruit extracted.
Table 1: The mass of dried extracted material, the concentration of the extracts after resuspension, antioxidant capacities and qualitative phytochemical screening of the solvent extracts.

\begin{tabular}{cccccc}
\hline & M & W & E & C & H \\
\hline $\begin{array}{c}\text { Mass dried extract }(\mathbf{m g}) \\
\text { Resuspended extract }\end{array}$ & 108 & 118 & 69 & 43 & 55 \\
$\begin{array}{c}\text { concentration }(\mathrm{mg} / \mathrm{mL}) \\
\text { Antioxidant capacity }(\boldsymbol{\mu g} \text { ascorbic } \\
\text { acid equivalents in extract) }\end{array}$ & 38 & 55 & 48 & 1.2 & 0.6 \\
$\begin{array}{c}\text { Total phenolics } \\
\text { Water soluble phenolics }\end{array}$ & +++ & +++ & + & - & - \\
Water insoluble phenolics & + & + & - & - & - \\
Cardiac glycosides & - & - & - & - & - \\
$\quad$ Saponins & + & ++ & - & - & - \\
$\quad \begin{array}{c}\text { Triterpenoids } \\
\text { Phytosterols }\end{array}$ & - & - & - & - & - \\
Alkaloids (Mayer test) & - & - & - & - & - \\
Alkaloids (Wagner test) & - & - & - & - & - \\
$\quad$ Flavonoids & - & - & - & - & - \\
$\quad$ Tannins & ++ & +++ & + & - & - \\
Anthraquinones & ++ & ++ & ++ & - & - \\
\hline
\end{tabular}

+++ indicates a large response; ++ indicates a moderate response; + indicates a minor response; - indicates no response in the assay; $\mathrm{M}=$ methanol extract; $\mathrm{W}=$ aqueous extract; $\mathrm{E}=$ ethyl acetate extract; $\mathrm{C}=$ chloroform extract; $\mathrm{H}=$ hexane extract.

\section{Antimicrobial activity}

Aliquots $(10 \mu \mathrm{L})$ of each extract were tested in the disc diffusion assay against panels of Gram negative (Figure 1) and Gram positive bacteria (Figure 2), as well as fungi (Figure 3). The methanol and water extracts displayed particularly broad speficity inhibitory activity against Gram negative bacteria, each inhibiting the growth of all of the Gram negative bacterial species tested (Figure 1). The methanol extract was generally more effective at inhibiting Gram negative bacterial growth than was the aqueous extract (as determined by zones of inhibition). The ethyl acetate extract also displayed broad specificity, inhibiting the growth of 7 of the 8 Gram negative bacteria tested (88\%), albeit with substantially smaller zones of inhibition (ZOIs). Proteus mirabilis was particularly susceptible, with ZOIs of approximately $12 \mathrm{~mm}$ against the methanolic extract. The chloroform and hexane extracts were generally devoid of inhibitory activity. Indeed, the chloroform extract was only able to inhibit A. hydrophilia growth, with ZOIs indicative of only weak inhibitory activity, whilst the hexane extract was completely devoid of activity.

Interestingly, the potency of the extracts was often better than that of the conventional antibiotics. Indeed, the methanolic extract was a substantially better inhibitor of $A$. hydrohilia, $P$. vulgaris and $P$. fluorescens growth than the ampicillin positive control. Similarly, the methanolic extract displayed similar efficacy as ampicillin towards P. mirabilis and $S$. salford growth. These results are noteworthy as the ampicillin discs used in this study contained a pure compound at a relatively high dose $(10 \mu \mathrm{g} / \mathrm{disc})$. In comparison, the extracts are crude mixtures and any antibacterial compounds would be expected to be a minor component of the extract. Chloramphenicol $(10 \mu \mathrm{g} / \mathrm{disc})$ was a good growth inhibitor of all bacteria.

The methanol and water extracts also inhibited growth of all of the Gram positive bacterial species tested. Ethyl acetate and chloroform were also effective growth inhibitors of 2 bacterial species each ( $S$. aureus and 


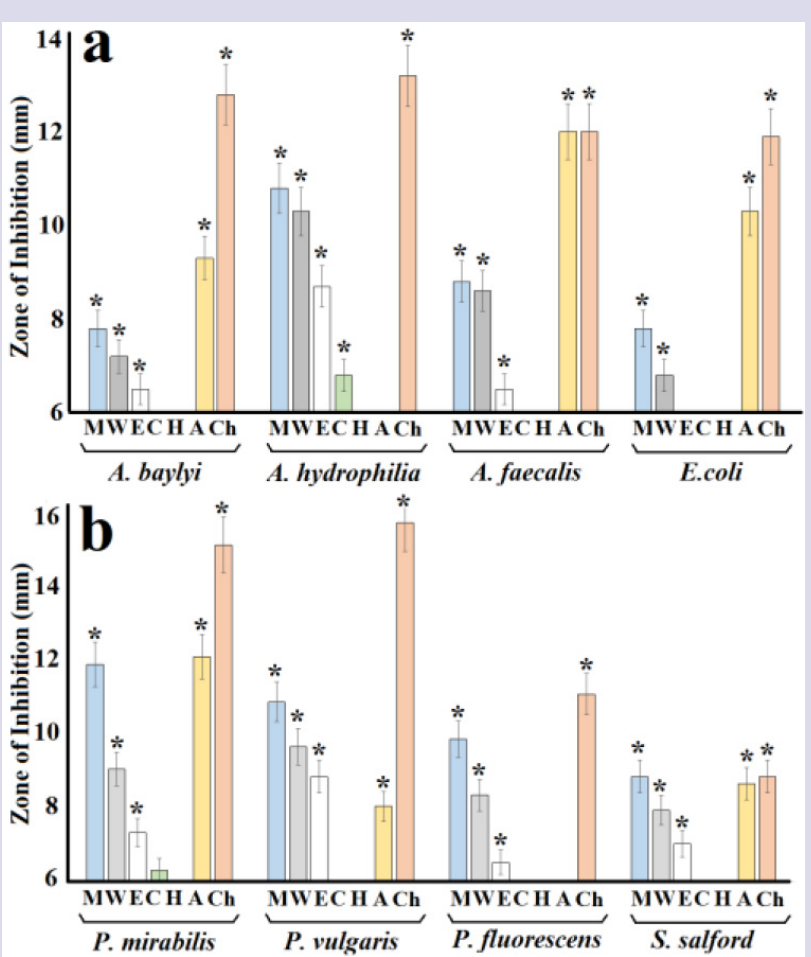

Figure 1: Antibacterial activity of B. obovata fruit extracts and ampicillin and chloramphenicol controls $(10 \mu \mathrm{g})$ measured as zones of inhibition $(\mathrm{mm})$ against Gram negative bacteria. $\mathrm{M}=$ methanolic extract; $\mathrm{W}=$ aqueous extract; $\mathrm{E}=$ ethyl acetate extract; $\mathrm{C}=$ chloroform extract; $\mathrm{H}=$ hexane extract; $\mathrm{A}=$ ampicillin; $\mathrm{Ch}=$ chloramphenicol. Results are expressed as mean \pm SEM of at least three determinations in triplicate $(n=9) .{ }^{*}$ indicates results that are significantly different to the untreated control $(p<0.01)$.

S. epidermidis). It is noteworthy that whilst growth inhibition was detected for several Gram positive bacteria, the relatively small ZOIs indicated that this inhibition was not particularly strong against $B$. cereus and S. pyogenes. The hexane extract inhibited only a single Gram positive bacterial species (S. epidermidis), with a small ZOI.

Broad spectrum growth inhibitory activity was detected for the methanolic extract against the tested fungal species, with all fungi tested susceptible to that extract. However, it is notable that only relatively small ZOIs were measured against all fungi, indicating only relatively weak antifungal activity. However, these fungal species were also quite resistant to the positive control nystatin $(100 \mu \mathrm{g})$, with only relatively small ZOIs measured. The aqueous extract also inhibited both C. albicans and S. cerevisiae, albeit with only small ZOIs, indicating that growth inhibition was not particularly strong for any extract against any of the fungi.

The relative level of antimicrobial activity was further evaluated by determining the MIC values (Table 2) for each extract against the bacterial and fungal species which were shown to be susceptible by disc diffusion assays. Most of the extracts were effective at inhibiting microbial growth at low concentrations, with MIC values against the bacterial species that they inhibited generally substantially $<1000 \mu \mathrm{g} / \mathrm{mL}(<10 \mu \mathrm{g}$ impregnated in the disc), indicating the potent antimicrobial activity of these extracts. These MIC values compare favourably with the dosages of the pure standards ampicillin, chloramphenicol and nystatin which was tested using 10, 10 and $100 \mu \mathrm{g}$ per disc respectively. The methanolic and aqueous extracts were particularly potent, achieving MIC values in the range of

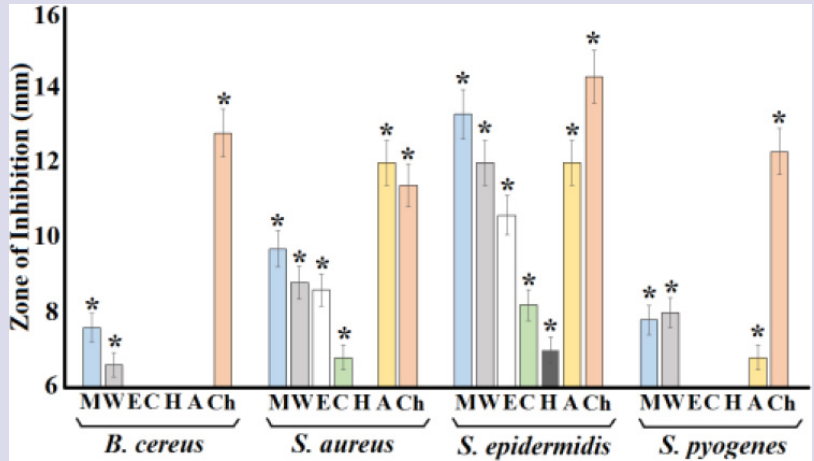

Figure 2: Antibacterial activity of $B$. obovata fruit extracts ampicillin and chloramphenicol controls (10 $\mu \mathrm{g})$ measured as zones of inhibition $(\mathrm{mm})$ against Gram positive bacteria. $\mathrm{M}=$ methanolic extract; $\mathrm{W}=$ aqueous extract; $\mathrm{E}=$ ethyl acetate extract; $\mathrm{C}=$ chloroform extract; $\mathrm{H}$ $=$ hexane extract; $\mathrm{A}=$ ampicillin; $\mathrm{Ch}=$ chloramphenicol. Results are expressed as mean \pm SEM of three determinations in triplicate $(n=9)$. * indicates results that are significantly different to the untreated control $(p<0.01)$

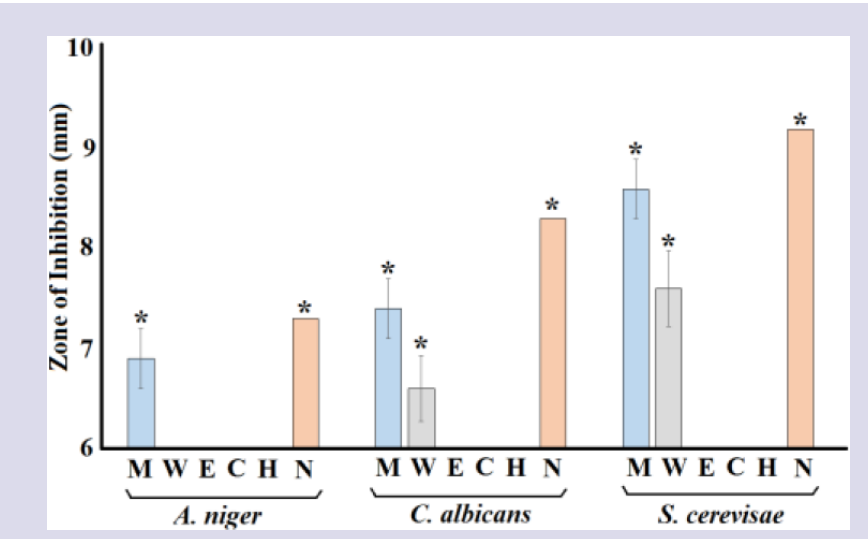

Figure 3: Antifungal activity of B. obovata fruit extracts and a nystatin control $(100 \mu \mathrm{g})$ measured as zones of inhibition $(\mathrm{mm}) . \mathrm{M}=$ methanolic extract; $\mathrm{W}=$ aqueous extract; $\mathrm{E}=$ ethyl acetate extract; $\mathrm{C}=$ chloroform extract; $\mathrm{H}=$ hexane extract; $\mathrm{N}=$ nystatin. Results are expressed as mean \pm SEM of three determinations in triplicate $(n=9)$. * indicates results that are significantly different to the untreated control $(p<0.01)$.

$50-500 \mu \mathrm{g} / \mathrm{mL}$ against several bacterial species. Whilst the ethyl acetate extract also had broad spectrum inhibitory activity, they generally had much lower efficacies.

\section{Anti-Giardial activity}

B. obovata fruit extracts were screened for their ability to inhibit Giardia duodenalis growth (Figure 4). Whilst the methanol and water extracts displayed significant inhibitory activity, the level of inhibition was relatively low ( $<20 \%$ inhibition of proliferation), indicating only weak growth inhibitory activity. Indeed, as inhibition of G. duodenalis growth did not exceed $50 \%$ at an concentration tested, it was not possible to determine an $\mathrm{IC}_{50}$ values for these extracts. The ethyl acetate, chloroform and hexane extracts were ineffective as proliferation inhibitors, with no significant difference to the untreated control levels. 
Table 2: Minimum inhibitory activity $(\mathrm{ug} / \mathrm{mL})$ of B. obovata fruit extracts against susceptible microbial species.

\begin{tabular}{|c|c|c|c|c|c|c|c|c|c|}
\hline & Pathogen & $M$ & w & $E$ & C & $\mathrm{H}$ & Amp & $\mathrm{Chl}$ & Nys \\
\hline \multirow{7}{*}{ 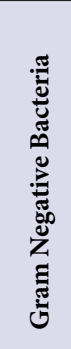 } & A. baylyi & 1125 & 1318 & 1832 & - & - & ND & ND & NT \\
\hline & A. hydrophilia & 300 & 328 & 620 & 1184 & - & - & ND & NT \\
\hline & A. faecalis & 270 & 352 & 980 & - & - & ND & ND & NT \\
\hline & E. coli & 1478 & 2264 & - & - & - & ND & ND & NT \\
\hline & P. mirabilis & 340 & 773 & 1200 & 2836 & - & ND & ND & NT \\
\hline & P. vulgaris & 430 & 722 & 935 & - & - & ND & $\mathrm{ND}$ & NT \\
\hline & P. fluorescens & 200 & 487 & 1160 & - & - & - & $\mathrm{ND}$ & NT \\
\hline \multirow{5}{*}{ 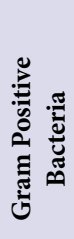 } & S. salford & 50 & 452 & 773 & - & - & ND & ND & NT \\
\hline & B. cereus & 1486 & 2566 & - & - & - & - & $\mathrm{ND}$ & NT \\
\hline & S. aureus & 670 & 700 & 728 & 1156 & - & ND & ND & NT \\
\hline & S. epidermidis & 540 & 683 & 902 & 1087 & 1365 & ND & ND & NT \\
\hline & S. pyogenes & 1120 & 995 & - & - & - & ND & ND & NT \\
\hline \multirow{3}{*}{ 总 } & A. niger & 1280 & - & - & - & - & NT & NT & ND \\
\hline & C. albicans & 865 & 1458 & - & - & - & NT & NT & ND \\
\hline & S. cerevisae & 655 & 882 & - & - & - & NT & NT & ND \\
\hline
\end{tabular}

Numbers indicate the mean MIC of three independent experiments in triplicate $(n=9) . \quad M=$ methanolic extract; $W=$ aqueous extract; $\mathrm{E}=$ ethyl acetate extract; $\mathrm{C}=$ chloroform extract; $\mathrm{H}=$ hexane extract; - indicates no growth inhibition; $\mathrm{ND}=$ not determined as the control antibiotics were tested at a single dose; $\mathrm{NT}=$ not tested; $\mathrm{Amp}=$ ampicillin; $\mathrm{Chl}=$ chloramphenicol; Nys $=$ nystatin .

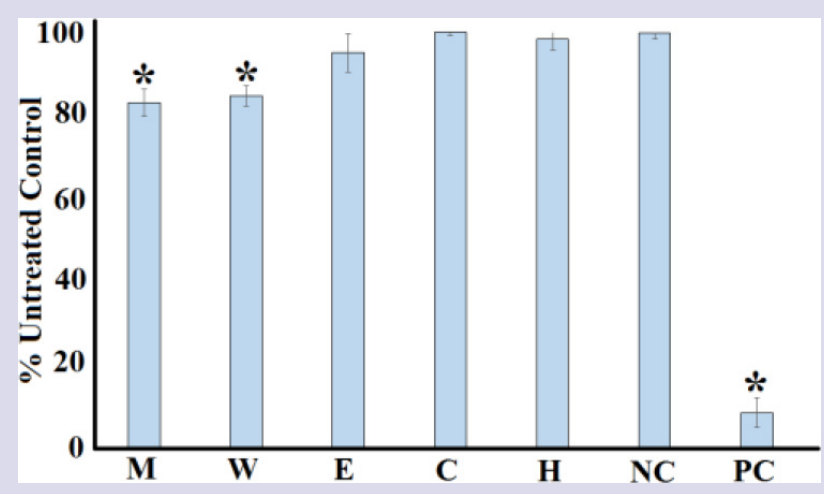

Figure 4: Inhibitory activity of B. obovata fruit extracts against Giardia duodenalis trophozoites measured as a percentage the untreated control. $\mathrm{M}=$ methanolic extract; $\mathrm{W}=$ aqueous extract; $\mathrm{E}=$ ethyl acetate extract; $\mathrm{C}=$ chloroform extract; $\mathrm{H}=$ hexane extract; $\mathrm{NC}=$ untreated (seawater) control; $\mathrm{PC}=$ metranidazole positive control. Results are expressed as mean percentages \pm SEM of three experiments in triplicate $(n=9) .{ }^{*}$ indicates results that are significantly different to the untreated control $(p<0.01)$.

\section{Inhibition of cancer cell proliferation}

The B. obovata fruit extracts were tested against 2 cancer cell lines (Caco2 human colorectal carcinoma cells, Figure 5; HeLa human cervical cancer cells, Figure 6) to determine their effects on cell proliferation. The methanol and water extracts displayed potent inhibitory activity against Caco2 cells, inhibiting proliferation by approximately $80 \%$ and $72 \%$ of the untreated control cell growth respectively (Figure 5). Whilst exposure to the ethyl acetate chloroform and hexane extracts also caused significant decreases in cellular proliferation $(11 \%, 11 \%$ and $7 \%$ respectively), the effects were relatively moderate compared to the methanolic

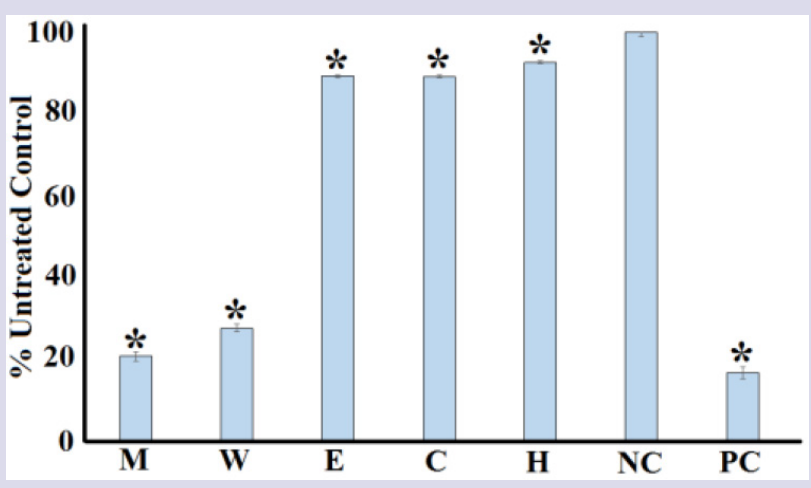

Figure 5: Anti-proliferative activity of $B$. obovata fruit extracts and untreated controls against $\mathrm{Caco} 2$ cancer cell lines measured as percentages of the untreated control cells. $\mathrm{M}=$ methanolic extract; $\mathrm{W}=$ aqueous extract; $\mathrm{E}=$ ethyl acetate extract; $\mathrm{C}=$ chloroform extract; $\mathrm{H}$ $=$ hexane extract; $\mathrm{NC}=$ untreated (seawater) control; $\mathrm{PC}=$ cisplatin positive control. Results are expressed as mean percentages \pm SEM of at three experiments in triplicate $(n=9) .{ }^{*}$ indicates results that are significantly different to the untreated control $(p<0.01)$. 


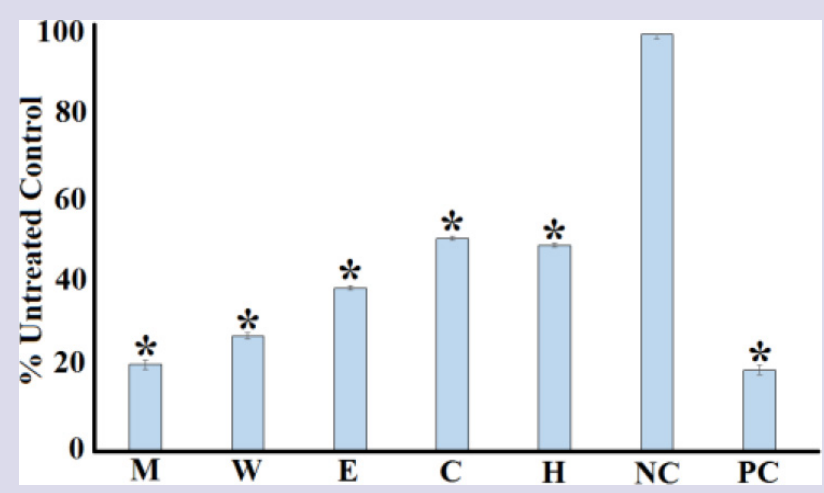

Figure 6: Anti-proliferative activity of B. obovata fruit extracts and untreated controls against HeLa cancer cell lines measured as percentages of the untreated control cells. $\mathrm{M}=$ methanolic extract; $\mathrm{W}=$ aqueous extract; $\mathrm{E}=$ ethyl acetate extract; $\mathrm{C}=$ chloroform extract; $\mathrm{H}$ $=$ hexane extract; $\mathrm{NC}=$ untreated (seawater) control; PC = cisplatin positive control. Results are expressed as mean percentages \pm SEM of at three experiments in triplicate $(n=9) .{ }^{*}$ indicates results that are significantly different to the untreated control $(p<0.01)$.

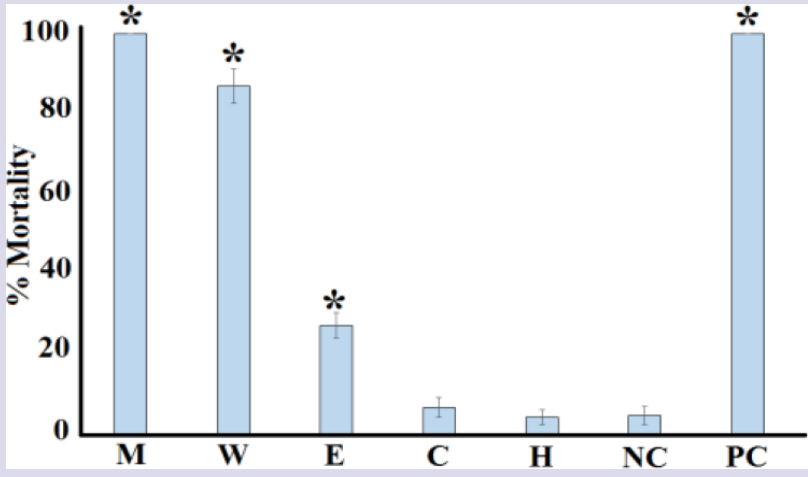

Figure 7: The lethality of $B$. obovata fruit extracts $(2000 \mu \mathrm{g} / \mathrm{mL})$ and potassium dichromate control $(1000 \mu \mathrm{g} / \mathrm{mL})$ towards Artemia franciscana nauplii after $24 \mathrm{hrs}$ exposure. $\mathrm{M}=$ methanolic extract; $\mathrm{W}=$ aqueous extract; $\mathrm{E}=$ ethyl acetate extract; $\mathrm{C}=$ chloroform extract; $\mathrm{H}$ $=$ hexane extract; $\mathrm{NC}=$ untreated (seawater) control; $\mathrm{PC}=$ positive (potassium dichromate) control. Results are expressed as mean \pm SEM of at least triplicate determinations. ${ }^{*}$ indicates results that are significantly different to the untreated control $(p<0.01)$.

Table 3: The $\mathrm{IC}_{50}$ values $(\mu \mathrm{g} / \mathrm{mL})$ of G. duodenalis and Caco2 and HeLa cancer cell lines and the $\mathrm{LC} \mathrm{C}_{50}$ values ( $\mu \mathrm{g} / \mathrm{mL}$ ) for Artemia franciscana nauplii exposed to $B$. obovata fruit extracts and control solutions.

\begin{tabular}{|c|c|c|c|c|c|c|c|}
\hline \multirow{2}{*}{ Bioassay } & \multirow[b]{2}{*}{ Methanol } & \multicolumn{3}{|c|}{ Solvent Extracts } & \multicolumn{2}{|r|}{ Controls } & \multirow[b]{2}{*}{ Positive control* } \\
\hline & & Water & Ethyl Acetate & Chloroform & Hexane & Negative Control & \\
\hline Giardia duodenalis $\mathrm{IC}_{50}$ & WND & WND & NA & NA & NA & - & 16 \\
\hline Caco2 cells $\mathrm{IC}_{50}$ & 480 & 563 & NA & NA & NA & - & 69 \\
\hline HeLa cells $\mathrm{IC}_{50}$ & 550 & 695 & 640 & 1486 & 1294 & - & 85 \\
\hline Artemia franciscana nauplii $24 \mathrm{~h} \mathrm{LC}_{50}$ & 450 & 590 & 645 & NA & NA & - & 156 \\
\hline
\end{tabular}

Numbers indicate the mean $\mathrm{IC}_{50}$ or $\mathrm{LC}_{50}$ values of three experiments performed in triplicate $(\mathrm{n}=9)$. - indicates no significant growth inhibition/ brine shrimp mortality; NA indicates that the extract was not significantly different from the negative control at any concentration tested, therefore an $\mathrm{IC}_{50}$ value was not able to be determined; WND indicates an $\mathrm{IC}_{50}$ was not determined as the amount of live Giardia did not reach $\leq 50 \%$ at any concentration tested; ${ }^{*}$ positive controls used for the Giardia, cancer proliferation and toxicity assays were metronidazole, cisplatin and potassium dichromate respectively.

proliferation by approximately 61,49 and 51\% inhibition respectively). Inhibition of proliferation by all extracts was dose dependent, with the level of inhibitory activity decreasing at lower concentrations.

\section{Quantification of toxicity}

The B. obovata fruit extracts were diluted to $4000 \mu \mathrm{g} / \mathrm{mL}$ (to give a bioassay concentration of $2000 \mu \mathrm{g} / \mathrm{mL}$ ) in artificial seawater for toxicity testing in the Artemia nauplii lethality bioassay. The reference toxin potassium dichromate was also tested in the bioassay at $1000 \mu \mathrm{g} / \mathrm{mL}$. Potassium dichromate was rapid in its induction of mortality, with significant mortality noted by $4 \mathrm{hrs}$ of exposure (unpublished results). The B. obovata fruit extracts were substantially slower at inducing mortality, with $\geq 12 \mathrm{hrs}$ needed for mortality induction to become evident. Despite the slower onset of mortality, the methanol, water and ethyl acetate extracts induced mortality significantly above that of the artificial seawater control (Figure 7). Table 3 shows the extract and control toxin concentrations required to achieve $50 \%$ mortality $\left(\mathrm{LC}_{50}\right.$ ) following $24 \mathrm{hrs}$ exposure. As toxicity of crude plant extracts has previously been defined as $24 \mathrm{LC}_{50}$ values $<1000 \mu \mathrm{g} / \mathrm{mL},{ }^{20}$ the measured $\mathrm{LC}_{50}$ values indicate that the methanol, water and ethyl acetate extracts display significantly toxicity. Whilst Artemia nauplii are generally considered to be robust, they are sensitive to acidic $\mathrm{pHs}^{21}$ and previous studies have reported that extracts containing high ascorbic acid levels may provide fallacious toxicity results ${ }^{21-22}$ Interestingly, the extracts displaying significant toxicity also correlated with high ascorbic acid equivalent levels (7-12 mg ascorbic acid equivalents per gram of original plant material extracted). Thus, this assay may have overestimated the toxicity of these extracts.

\section{DISCUSSION}

B. obovata fruit was used by the first Australians to treat sores and ulcers, eye and skin diseases and for the treatment of diarrhoea. ${ }^{12}$ The current study was undertaken to examine the antimicrobial and anticancer activities of various B. obovata fruit extracts and their toxicity. Bacterial growth was inhibited in both Gram positive and Gram-negative bacteria by the B. obovata fruit extracts, although the Gram negative bacteria were slightly more susceptible. In our study, we have reported growth inhibitory activity of the $B$. obovata fruit extracts towards several Gram-negative bacteria. A. hydrophilia (MIC $=300 \mu \mathrm{g} / \mathrm{mL})$, A. faecalis $(\mathrm{MIC}=270 \mu \mathrm{g} / \mathrm{mL})$, P. mirabilis $(\mathrm{MIC}=340 \mu \mathrm{g} / \mathrm{mL})$, . vulgaris $(\mathrm{MIC}=430 \mu \mathrm{g} / \mathrm{mL})$, P. fluorescens $(\mathrm{MIC}=200 \mu \mathrm{g} / \mathrm{mL})$ and S. salford growth $(\mathrm{MIC}=50 \mu \mathrm{g} / \mathrm{mL})$ were particularly strongly inhibited. Moderate inhibitory activity was noted against A. baylyi and E. coli, with MIC values $>1000 \mu \mathrm{g} / \mathrm{mL}$. Of the Gram-positive bacteria, the Staphylococcus species were most susceptible to the B. obovata fruit extracts, with MIC values of 670 and $540 \mu \mathrm{g} / \mathrm{mL}$ determined for the methanolic extract.

The ability of plant extracts to inhibit the growth of both Gram positive and Gram-negative bacteria has been previously reported for other 
plants that have a history of medicinal usage for the treatment of microbial diseases. The antiseptic properties of the Eucalyptus spp. ${ }^{23}$ Leptospermum spp. ${ }^{24}$ and Syzygium spp. ${ }^{25-27}$ have been studied extensively and shown to inhibit the growth of a wide variety of bacteria. However, the equal or greater susceptibility of the Gram-negative bacterial species towards the B. obovata fruit extracts is noteworthy. This is in contrast to other previous studies which have reported a greater susceptibility of Gram positive bacteria towards solvent extracts for South American, ${ }^{28}$ African ${ }^{29}$ and Australian ${ }^{30}$ plant extracts, although other examples of plants having a greater effect on Gram negative bacteria have also been reported. ${ }^{10,14}$

Antifungal activity was also noted for the methanolic and aqueous B. obovata fruit extracts. The methanolic extract was a particularly good inhibitor of C. albicans and C. cerevisiae growth, with MIC values of 865 and $655 \mu \mathrm{g} / \mathrm{mL}$ respectively. Interestingly, the methanolic extract also inhibited the growth of $A$. niger, with an MIC of $1280 \mu \mathrm{g} / \mathrm{mL}$. Whilst this is substantially higher than against the other fungal strains, this inhibition is still noteworthy as the A. niger tested in our studies is a strain has previously been reported to be resistant to several antibiotics. ${ }^{31-32}$

Identification of the specific components responsible for the antimicrobial activity reported in of the B. obovata fruit extracts was beyond the scope of our study. However, the qualitative phytochemical screening studies show that the most potent methanolic and aqueous extracts were rich in phenolics, flavonoids and tannins. Many studies have reported potent growth inhibitory activities for a wide variety of flavonoids against extensive bacterial panels. ${ }^{33}$ Similarly, a number of tannin compounds have bacterial growth inhibitory activity. Gallotannins have been reported to inhibit the growth of a broad spectrum of bacterial species $^{34}$ through a variety of mechanisms including binding cell surface molecules including lipotoichoic acid and proline-rich cell surface proteins $s^{35,36}$ and by inhibiting glucosyltransferase enzymes. ${ }^{37}$ Elligitannins are also highly potent inhibitors of bacterial growth, with MIC values as low as $62.5 \mu \mathrm{g} / \mathrm{mL} .{ }^{34,36}$ Ellagitannins have also been reported to function via several antibiotic mechanisms including interaction with cytoplasmic oxidoreductases and by disrupting bacterial cell walls. ${ }^{34,36}$ Thus, it is likely that multiple compounds within the B. obovata fruit extracts contribute to the antimicrobial properties of these extracts.

Antiproliferative activity against $\mathrm{Caco}_{2}$ and $\mathrm{HeLa}$ carcinoma cell lines was also noted for the B. obovata fruit extracts (especially for the methanol and water extracts), with $\mathrm{IC}_{50}$ values generally approximately $500-700 \mu \mathrm{g} / \mathrm{mL}$. The ethyl acetate extract was also a potent inhibitor of HeLa proliferation $\left(\mathrm{IC}_{50} 640 \mu \mathrm{g} / \mathrm{mL}\right)$, although it was completely ineffective against $\mathrm{Caco}_{2}$ proliferation. Whilst the chloroform and hexane extracts were also completely ineffective against $\mathrm{Caco}_{2}$ cell proliferation, they were moderate inhibitors of HeLa proliferation, with $\mathrm{IC}_{50}$ values of 1486 and $1294 \mu \mathrm{g} / \mathrm{mL}$ respectively. Interestingly, the antiproliferative activity correlated to the extracts with the highest antioxidant capacity. Previous studies have noted a similar relationship between antioxidant capacity and antiproliferative activity in $\mathrm{Caco} 2$ cells. ${ }^{13,38}$ Both of those studies postulate that the antiproliferative (and antioxidant) activities were due to the phenolic acids and flavonoids in the extracts. This is consistent with the qualitative phytochemical analysis in our study, which observed high relative abundances of both classes of compounds in the methanolic, aqueous and ethyl acteate B. obovata fruit extracts and an absence of detectable levels of the compound classes in the chloroform and hexane extracts. Flavonoids are believed to protect cells from disease by shielding lipids, proteins and DNA from oxidative damage. ${ }^{39}$ The specific extract components responsible for the antiproliferative activity of the B. obovata extracts were not identified in our study and further work is required to isolate and identify those compounds.

The findings reported here also show that only the B. obovata methanol, water and ethyl acetate extracts displayed significant toxicity towards
A. franciscana, with $\mathrm{LC}_{50}$ values of 450,590 and $645 \mu \mathrm{g} / \mathrm{mL}$ respectively. Whilst otherwise quite hardy, Artemia nauplii have been shown in our laboratory to be sensitive to $\mathrm{pH}$ changes (unpublished results). Extract constituents such as ascorbic acid, gallic acid and other tannins would be expected to decrease the $\mathrm{pH}$ of the test solution and may account for any apparent toxicity. As these extracts would be expected to contain significant quantities of ascorbic acid and tannins, it is perhaps not surprising that they displayed significant toxicity in this assay. Further toxicity studies using human cell lines are needed to further determine the suitability of the B. obovata fruit extracts for medicinal purposes.

The results of this study indicate that the B. obovata fruit extracts examined in this report are worthy of further study due to their antibacterial activity and ability to block cancer cell proliferation. Further evaluation of the antimicrobial and anticancer properties of these extracts is warranted. Likewise, purification and identification of the bioactive components is needed to examine the mechanisms of action of these agents. Whilst the extracts examined in this report have potential as antimicrobial and anticancer agents, caution is needed before they can be applied to medicinal purposes.

\section{CONCLUSION}

The results of this study partially validate the traditional usage of $B$. obovata fruit extracts to treat microbial diseases and cancer and indicate that they are worthy of further study. Bioactivity driven purifications of the active components and an examination of the mechanisms of action of these agents is required.

\section{ACKNOWLEDGEMENT}

We are grateful to Gayangwa and Gwen Lalara and other members of the Warnindhilyagwa tribe of Groote Esylandt for identifying and providing the B. obovata fruit used in this study. We also thank David Boehme of Northern Territory Wild Harvest for facilitating Dr Cock's visit to Groote Esylandt and arranging a meeting with the Warnindhilyagwa tribal elders. We are also grateful to Ann McDonnell for providing the G. duodenalis used in these studies. Financial support for this work was provided by the Environmental Futures research Institute and the School of Environment and Science, Griffith University.

\section{CONFLICT OF INTEREST}

The authors declare no conflict of interest.

\section{ABBREVIATIONS}

DMSO: Dimethyl sulfoxide; $\mathbf{I C}_{50}$ : The concentration required to achieve a $50 \%$ reduction in proliferation; $\mathbf{L C}_{50}$ : The concentration required to achieve $50 \%$ mortality; MIC: minimum inhibitory concentration; ZOI: zone of inhibition.

\section{REFERENCES}

1. Mandeville A, Cock IE. Terminalia chebula Retz. fruit extracts inhibit bacteria triggers of some autoimmune diseases and potentiate the activity of tetracycline. Indian Journal of Microbiology. 2018;58(4):496-506. DOI: 10.1007/s12088-0180754-9

2. Hutchings A, Cock IE. An interactive antimicrobial activity of Embelica officinalis Gaertn. fruit extracts and conventional antibiotics against some bacterial triggers of autoimmune inflammatory diseases. Pharmacognosy Journal. 2018;10(4):654-62. DOI: 10.5530/pj.2018.4.108

3. Cock IE, Vuuren SFV. The potential of selected some South African plants with anti-Klebsiella activity for the treatment and prevention of ankylosing spondylitis. Inflammopharmacology. 2015;23(1):21-35. DOI: 10.1007/s10787-014-0222-z

4. Cock IE, Vuuren SFV. Anti-Proteus activity of some South African medicinal plants: Their potential for the treatment and prevention of rheumatoid arthritis. Inflammopharmacology. 2014;22(1):23-36. DOI 10.1007/s10787-013-0179-3.

5. Cock IE, Selesho MI, Vuuren SFV. A review of the traditional use of southern 
African medicinal plants for the treatment of selected parasite infections affecting humans. Journal of Ethnopharmacology. 2018;220:250-64. DOI: 10.1016/j. jep.2018.04.001

6. Sirdaarta J, Matthews B, Cock IE. Inhibitory activity of Kakadu plum fruit extracts against microbial triggers of rheumatoid arthritis: Identification of stilbene and tannin components. Journal of Functional Foods. 2015:17:610-20. DOI: 10.1016/j.jff.2015.06.019

7. Cock IE, Winnett V, Sirdaarta J, et al. The potential of selected Australian medicinal plants with anti-Proteus activity for the treatment and prevention of rheumatoid arthritis. Pharmacognosy Magazine. 2015;11(42 Suppl):S190-208. DOI: 10.4103/0973-1296.157734

8. Rayan P, Matthews B, McDonnell A, et al. Phytochemical analysis of Tasmannia lanceolata extracts and inhibition of Giardia duodenalis proliferation. Pharmacognosy Journal. 2016;8(3):291-9. DOI: 10.5530/pj.2016.3.19

9. Rayan P, Matthews B, McDonnell A, et al. Terminalia ferdinandiana extracts as inhibitors of Giardia duodenalis proliferation: a new treatment for giardiasis Parasitology Research. 2015;114(7):2611-20. DOI 10.1007/s00436-015-4465-4

10. Cock IE, Kukkonen L. An examination of the medicinal potential of Scaevola spinescens: Toxicity, antibacterial and antiviral activities. Pharmacognosy Research. 2011;3(2):85-94. DOI: 10.4103/0974-8490.81955

11. Shalom J Cock IE. Terminalia ferdinandiana Exell. fruit and leaf extracts inhibit proliferation and induce apoptosis in selected human cancer cell lines. Nutrition and Cancer. 2018;70(4):579-93. DOI: 10.1080/01635581.2018.1460680

12. Lassak EV, McCarthy T. Australian medicinal plants. New Holland Publishers. Australia. 2011.

13. Jamieson N, Sirdaarta J, Cock IE. The anti-proliferative properties of Australian plants with high antioxidant capacities against cancer cell lines. Pharmacognosy Communications. 2014;4(4):71-82. DOI: 10.5530/pc.2014.4.8

14. Vesoul J, Cock IE. An examination of the medicinal potential of Pittosporum phylloraeoides: Toxicity, antibacterial and antifungal activities. Pharmacognosy Communications. 2011;1(2):8-17. DOI: 10.5530/pc.2011.2.3

15. Kalt FR, Cock IE. GC-MS analysis of bioactive Petalostigma extracts: Toxicity, antibacterial and antiviral activities. Pharmacognosy Magazine. 2014;10(37 Suppl):S37-48. DOI: 10.4103/0973-1296.127338

16. Winnett $\mathrm{V}$, Boyer $\mathrm{H}$, Sirdaarta J, et al. The potential of Tasmannia lanceolata as a natural preservative and medicinal agent: Antimicrobial activity and toxicity. Pharmacognosy Communications. 2014;4(1):42-52. DOI: 10.5530/pc.2014.1.7

17. Hart C, Ilanko P, Sirdaarta J, et al. Tasmannia stipitata as a functional food/natural preservative: Antimicrobial activity and toxicity. Pharmacognosy Communications. 2014;4(4):33-47. DOI: 10.5530/pc.2014.4.4

18. Cock IE. Antimicrobial activity of Callistemon citrinus and Callistemon salignus methanolic extracts. Pharmacognosy Communications. 2012;2(3):50-7. DOI: 10.5530/pc.2012.3.11

19. Cock IE, Kalt FR. GC-MS analysis of a Xanthorrhoea johnsonii leaf extract displaying apparent anaesthetic effects. Journal of Natural Pharmaceuticals. 2012;3(2):78-88.

20. Cock IE, Ruebhart DR. Comparison of the brine shrimp nauplii bioassay and the ToxScreen-II Test for the detection of toxicity associated with Aloe vera (Aloe barbadensis Miller) leaf extract. Pharmacognosy Journal. 2009;1(2):98-101.

21. Kwast KE. Oxygen and $\mathrm{pH}$ regulation of protein synthesis in mitochondria from Artemia franciscana embryos. Biochemical Journal. 1996;313(1):207-13.

doi:10.1042/bj3130207.

22. Wright $\mathrm{MH}$, Lee $\mathrm{CJ}$, Pollock $\mathrm{CE}$, et al. Growth inhibitory activity of selected high antioxidant Australian Syzygium species against the food poisoning and tissue necrotic pathogen Clostridium perfringens. Pharmacognosy Communications. 2016;6(2):93-9. DOI:10.5530/ pc.2016.2.7

23. Cock IE. Antimicrobial activity of Eucalyptus major and Eucalyptus baileyana methanolic extracts. Internet Journal of Microbiology. 2009;6(1):1.

24. Cock IE. Antimicrobial activity of Leptospermum bracteata and Letptospermum juniperium methanolic extracts. Pharmacognosy Communications 2013;3(3):45-52 DOI: $10.5530 /$ pc.2013.3.9

25. Sautron C, Cock IE. Antimicrobial activity and toxicity of Syzygium australe and Syzygium leuhmanii fruit extracts. Pharmacognosy Communications. 2014;4(1):53-60. DOI: 10.5530/pc.2014.1.8

26. Chikowe G, Mpala L, Cock IE. Antibacterial activity of selected Australian Syzygium species. Pharmacognosy Communications. 2013:3(4):77-83. DOI: 10.5530/pc.2013.3.11

27. Mohanty S, Cock IE. Bioactivity of Syzygium jambos methanolic extracts: antibacterial activity and toxicity. Pharmacognosy Research. 2010;2(1):4-9. DOI: 10.4103/0974-8490.60577

28. Paz EA, Cerdeiras MP, Fernandez J, Ferreira F, Moyna P, Soubes M, et al. Screening of Uruguayan medicinal plants for antimicrobial activity. J Ethnopharmacol. 1995;45(1):67-70.

29. Vlietinck AJ, Hoof LV, Totte J, Lasure A, Vanden BD, Rwangabo PC, et al. Screening of a hundred Rwandese medicinal plants for antimicrobial and antiviral properties. J Ethnopharmacol. 1995:46(1):31-47.

30. Cock IE. Antibacterial activity of selected Australian native plant extracts. Internet Journal of Microbiology. 2008;4(2):2

31. Cock I, Mohanty S, White A, Whitehouse M. Colloidal silver (CS) as an antiseptic: Two opposing viewpoints. Pharmacognosy Communications. 2012;2(1):47-56. DOI: $10.5530 /$ pc. 2012.1 .9

32. Setzer MC, Setzer WN, Jackes BR, et al. The medicinal value of tropical rainforest plants from Paluma, North Queensland, Australia. Pharm Biol. $2001 ; 39(1): 67-78$

33. Narayana KR, Reddy MS Chaluvadi MR et al. Bioflavonoids classification, pharmacological, biochemical effects and therapeutic potential. Indian Journal of Pharmacology. 2001;33(1):2-16.

34. Buzzini P, Arapitsas P, Goretti M, et al. Antimicrobial activity of hydrolysable tannins. Mini-Reviews in Medicinal Chemistry. 2008;8(12):1179-87.

35. Wolinsky LE, Sote EO. Isolation of natural plaque-inhibiting substances from 'Nigerian chewing sticks'. Caries Research. 1984;18(3):216-25

36. Hogg SD, Embery G. Blood-group-reactive glycoprotein from human saliva interacts with lipoteichoic acid on the surface of Streptococcus sanguis cells. Archives in Oral Biology. 1982;27(3):261-8

37. Wu-Yuan CD, Chen CY, Wu RT. Gallotannins inhibit growth, water-soluble glucan synthesis and aggregation of Streptococci mutans. Journal of Dental Research. 1988;67(1):51-5.

38. Eberhardt MV, Lee CY, Liu RH. Nutrition: Antioxidant activity of fresh apples Nature. 2000;405(6789):903-4.

39. Chen AY, Chen YC. A review of the dietary flavonoid, kaempferol on human health and cancer prevention. Food Chemistry. 2013;138(4):2099-107.

\section{PICTORIAL ABSTRACT}

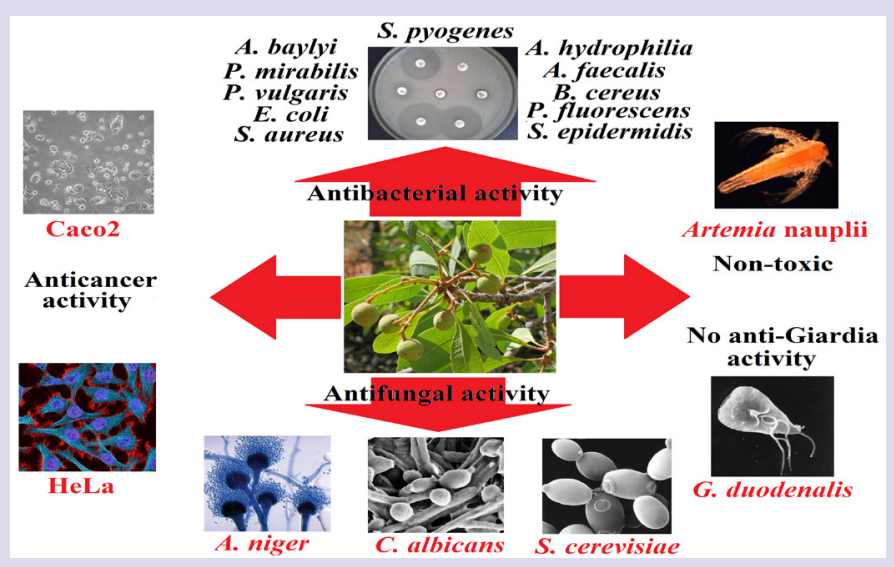

\section{SUMMARY}

- Methanolic, aqueous and ethyl acetate B. obovata fruit extracts were potent inhibitors of a panel of bacteria.

- The methanolic and aqueous extracts had the broadest spectrum, inhibiting all gram-positive and gram-negative bacteria tested.

- The methanolic extract also displayed good antifungal activity.

- The methanolic and aqueous extracts were also good inhibitors of $\mathrm{Caco} 2$ and HeLa carcinoma proliferation.

- None of the extracts significantly inhibited G. duodenalis gwowth

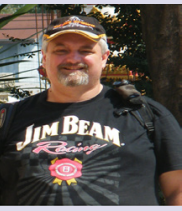

\section{ABOUT AUTHORS}

Dr lan Cock leads a research team in the Environmental Futures Research Institute and the School of Natural Sciences at Griffith University, Australia. His research involves bioactivity and phytochemical studies into a variety of plant species of both Australian and international origin, including Aloe vera, South Asian and South American tropical fruits, as well as Australia plants including Scaevola spinescens, Pittosporum phylliraeoides, Terminalia ferdinandiana (Kakadu plum), Australian Acacias, Syzygiums, Petalostigmas and Xanthorrhoea johnsonii (grass trees). This range of projects has resulted in nearly 200 publications in a variety of peer reviewed journals. 